\title{
Patterns of genome size variation in snapping shrimp
}

\begin{tabular}{|r|l|}
\hline Journal: & Genome \\
\hline Manuscript ID & gen-2015-0206.R1 \\
\hline Danuscript Type: & Article \\
\hline Complete List of Authors: & $\begin{array}{l}\text { Jeffery, Nicholas; Bedford Institute of Oceanography, Fisheries and Oceans } \\
\text { Canada } \\
\text { Hultgren, Kristin; Seattle University, Department of Biology } \\
\text { Chak, Solomon; Virginia Institute of Marine Science } \\
\text { Gregory, Ryan; University of Guelph, } \\
\text { Rubenstein, Dustin; Columbia University, Department of Ecology, Evolution } \\
\text { and Environmental Biology ; Columbia University, Center for Integrative } \\
\text { Animal Behavior }\end{array}$ \\
\hline Keyword: & \begin{tabular}{l} 
Synalpheus, genome size, C-value, polyploidy, chromsome \\
\hline
\end{tabular} \\
\hline \multicolumn{2}{|c}{} \\
\hline
\end{tabular}

SCHOLARONE $^{\text {m }}$

Manuscripts 


\section{Patterns of genome size variation in snapping shrimp}

Nicholas W. Jeffery ${ }^{1}$, Kristin Hultgren ${ }^{2}$, Solomon Tin Chi Chak ${ }^{3}$, T. Ryan Gregory ${ }^{1}$, Dustin R. Rubenstein $^{4,5}$

${ }^{1}$ Department of Integrative Biology, University of Guelph, Guelph, Ontario, Canada, N1G 2W1

${ }^{2}$ Department of Biology, Seattle University, Seattle, WA, 98122, USA

${ }^{3}$ Virginia Institute of Marine Science, The College of William and Mary, Gloucester Point, VA 23062, USA

${ }^{4}$ Department of Ecology, Evolution and Environmental Biology and ${ }^{5}$ Center for Integrative Animal Behavior, Columbia University, New York NY 10027, USA 


\begin{abstract}
Although crustaceans vary extensively in genome size, little is known about how genome size may affect the ecology and evolution of species in this diverse group, in part due to the lack of large genome size datasets. Here we investigate interspecific, intraspecific, and intra-colony variation in genome size in 39 species of Synalpheus shrimps, representing one of the largest genome size datasets for a single genus within crustaceans. We find that genome size ranges approximately 4-fold across Synalpheus with little phylogenetic signal, and is not related to body size. In a subset of these species, genome size is related to chromosome size, but not to chromosome number, suggesting that despite large genomes, these species are not polyploid. Interestingly, there appears to be 35\% intraspecific genome size variation in Synalpheus idios among geographic regions, and up to $30 \%$ variation in $S$. duffyi genome size within the same colony.
\end{abstract}

Keywords: Synalpheus, genome size, C-value, polyploidy, gene duplication, chromosome 


\section{Introduction}

Snapping shrimps in the genus Synalpheus (Alpheidae) are some of the most diverse and abundant decapod crustaceans inhabiting coral reef habitats across the globe (Felder and Chaney 1979). The clade referred to as the Synalpheus gambarelloides species group is restricted largely to the Caribbean and contains more than 45 currently described species (Hultgren and Duffy 2011, Morrison et al. 2004). Species in the gambarelloides group live symbiotically within the canals of marine sponges (Hultgren and Duffy 2012) and exhibit a wide range of body sizes, with bigger species generally inhabiting sponge species with larger canals (Hultgren and Duffy 2010). Although most well-known for their variation in social behavior, including the only known eusocial species in the marine environment (Duffy 1996, Duffy and Macdonald 2010, Hultgren et al. in press), increasing knowledge of phylogeny, biogeography, and host use of Synalpheus (Morrison et al. 2004, Macdonald et al. 2006, Hultgren and Duffy 2011, 2012, Duffy 1996) make them a potential model system for the study of speciation in the sea.

Phylogenetic data suggest that the gambarelloides group underwent a large and rapid diversification within the last 5-7 MYA, as well as a smaller diversification event $\sim 4$ MYA, most likely associated with reef changes caused by the formation of the Isthmus of Panama (Morrison et al. 2004). Early genetic studies on Synalpheus brooksi found some evidence for sponge hostassociated genetic divergence and the potential for cryptic speciation (Duffy 1993, 1996), and subsequent studies have provided additional evidence that different shrimp species are quite host specific, often only occupying one or a few sponge hosts throughout their geographic range (Macdonald et al. 2006, Hultgren and Duffy 2010). However, other mechanisms and processes that shaped the speciation and diversification of the Synalpheus gambarelloides species group remain largely unstudied.

In many taxa - particularly in plants — species divergence is associated with large changes in nuclear DNA content, either involving whole genome duplication (i.e. polyploidy; Wood et al. 2009) or large-scale transposable elements proliferation (Kidwell 2002, Piegu et al. 2006). Genome duplication as a mechanism of speciation is well recognized as being important in angiosperms and ferns (De Bodt et al. 2005, Soltis et al. 2009), but it tends to be rarer and more phylogenetically diffuse and restricted to examples of ancient genome duplication (paleopolyploidy) in animals (Gregory and Mable 2005). Moreover, genome duplication is better studied in plants than in animals, so it is likely that more examples await discovery. 
Genome size is often thought to be constant within a species (hence the term 'C-value'), but intraspecific variation in genome size has been reported in a number of animals (e.g. Tribolium beetles, Alvarez-Fuster et al. 1991; Drosophila, Ellis et al. 2014; caridean shrimp, Bonnivard et al. 2009). Although many cases of intraspecific variation in genome size may be the result of methodological errors in genome estimation (Greilhuber 1998) or occur between geographically isolated populations with some genetic differences separating them (Greilhuber 2005), there are a variety of mechanisms that can give rise to within-species variation in genome size, also known as “orthodox” variation in genome size (Greilhuber 1998).

Crustaceans exhibit extensive diversity in genome size, even within some major groups. Decapod crustaceans, for example, vary more than 40-fold in genome size among species (1.07 to $40.89 \mathrm{pg}$, where $1 \mathrm{pg}=978 \mathrm{Mb}$; Gregory 2015). In some groups, such as copepods, genome size is positively correlated with body size (Wyngaard and Rasch 2000, Wyngaard et al. 2005), a pattern thought to be driven by the correlation between genome size and cell size that can lead to larger bodies in groups with determinate growth. Genome size data are generally lacking for the alpheid shrimp, the most speciose family of shrimp and the one that includes Synalpheus. The four published estimates of genome size for alpheid shrimps range from 4.10 to $16.31 \mathrm{pg}$ (Bachmann and Rheinsmith 1973, Rheinsmith et al. 1974), though unpublished data suggest genome sizes ranges at least up to 29.05 pg (Alpheus simus; Jeffery and Hurt, unpublished data). Polyploidy is common in branchiopod crustaceans such as Daphnia (Dufresne and Hebert 1998) and Artemia (Zhang and King 1993), but it has not yet been described in decapod crustaceans. Recently, Rubenstein et al. (2008) observed evidence based on microsatellite duplications that was consistent with polyploidy or major genome duplication within Synalpheus.

Here we examine interspecific, intraspecific, and intra-colony variation in genome size among 39 species of Synalpheus snapping shrimp sampled from across the Caribbean. This dataset represents a first step towards exploring how genome size changes and/or genome duplications may have been associated with diversification in Synalpheus. In Synalpheus, body size is variable among species and crucially important in host use, as it not only limits the range of sponge hosts a particular shrimp species can use (Duffy 1993, Hultgren and Duffy 2010), but also mediates interspecific competition when multiple shrimp species inhabit an individual sponge (Hultgren and Duffy 2012). Thus, we also examine the relationship between genome and body size (i.e. carapace length), and explore the degree of phylogenetic signal in genome size. 
We also assess the potential correlates (geography, year) of intraspecific variation in genome size in the two shrimp species with some of the wideest geographic ranges and the largest and most variable genomes. Finally, to shed more light on ploidy levels in Synalpheus, we present preliminary data on chromosome number and size from four species with different genome sizes.

\section{Methods}

\section{Ethics statement}

All necessary permits for collecting and handling shrimps were obtained from the respective agencies. All animals were cared for according to the Guide for the Care and Use of Experimental Animals.

\section{Specimen collection}

Shrimp were collected from 1998 to 2014 in different regions in the Caribbean, including: Carrie Bow Cay, Belize; Bocas Del Toro, Panama; Discovery Bay, Jamaica; various sites on the southern side of Curaçao; Jardines de la Reina archipelago, Cuba; various sites on the southern side of Barbados; Lee Stocking Island, Bahamas; and Florida Keys, Florida, USA. Samples were preserved in $95 \%$ ethanol at room temperature $\left(20^{\circ} \mathrm{C}\right)$, and gills were dissected for genome size estimation. We measured body size as the maximum carapace length (in $\mathrm{mm}$ ) of the shrimp (for details see Duffy and Macdonald 2010).

Although prior studies suggest that variation in EtOH preservation time does not bias genome size estimates using Feulgen densitometry (Jeffery and Gregory 2014), because we were working with samples collected over a 12-year period, we tested whether preservation length could have influenced our genome size estimates by running a general linearized mixed model with time between preservation and analysis as a fixed effect, species as a random effect, and genome size as the dependent variable. We found no effect of preservation time on our genome size estimates $\left(\mathrm{F}_{1,364.1}=0.51, \mathrm{P}=0.48\right)$.

\section{Species identification}

Species were identified with light microscopy using recent taxonomic keys (Rios and Duffy 2007) and when necessary, validated using genetic barcoding (sensu Hultgren and Duffy 2011). For a subset of species that had wide geographic ranges and showed appreciable intraspecific 
variation in genome size ( $S$. idios and $S$. duffyi), we also sequenced the 5 ' barcoding region of the cytochrome oxidase I (COI) mitochondrial gene for a subset of individuals ( $S$. idios, $\mathrm{n}=11: S$. duffyi, $\mathrm{n}=12$ ) to test whether individuals with divergent genome sizes represented cryptic species (i.e. whether genome size divergence correlated with genetic divergence). DNA extraction, primers, and PCR protocols have been extensively described elsewhere (Hultgren and Duffy 2011). Briefly, we sequenced amplified PCR product on a Prism 3730xl sequencer (Applied Biosystems Inc.), and forward and reverse sequences were verified and trimmed using Sequencher v4.8 (Gene Codes Corporation). We calculated Kimura 2-parameter genetic distance using the program Mega v6.06 (Tamura et al. 2013).

\section{Genome size estimation}

Fixed gills were dissected on a glass microscope slide in $40 \%(\mathrm{v} / \mathrm{v})$ acetic acid to soften the tissue for Feulgen image analysis densitometry (FIAD) (Hardie et al. 2002). Gill tissue has previously been used in genome size studies in crustaceans, and is a diploid tissue whose nuclei show intermediate levels of compaction relative to muscle cells or haemolymph (Deiana et al. 1999, Jeffery and Gregory 2014). This method allowed us to avoid measuring any nuclei from endopolyploid tissues, which are common in crustaceans (Neiman et al. 2015). The resulting cell suspension was then flattened with a coverslip that was held onto the slide by three clothespins. Slides were frozen on dry ice for roughly $5 \mathrm{~min}$, after which time the coverslip was "flipped" off the slide using a razor blade. Each slide was immersed in 95\% EtOH for 1 min and allowed to air dry in the dark. Feulgen staining followed the protocol described in detail by Hardie et al. (2002). Briefly, slides were fixed in 85:10:5 methanol:formalin:glacial acetic acid overnight and rinsed in deionized water the following morning. The slides were then hydrolyzed in $5 \mathrm{~N} \mathrm{HCl}$ for $120 \mathrm{~min}$ at room temperature, followed by staining in Schiff reagent for $120 \mathrm{~min}$. This was followed by a series of bisulfite and deionized water rinses. Chicken (Gallus domesticus, $1 \mathrm{C}=$ $1.25 \mathrm{pg}$ ) erythrocytes were used as the primary standard, with rainbow trout (Oncorhynchus mykiss, $1 \mathrm{C}=2.60 \mathrm{pg}$ ) blood included as an additional check of staining reliability. All slides were analyzed with the Bioquant Life Science image analysis software using a Leica DM2500 microscope and a Retiga EXi digital camera. We measured a minimum of $20($ mean $=33)$ nuclei per slide. 
To validate our FIAD measurements, we also estimated genome size of live specimens using flow cytometry for two species, $S$. brooksi and $S$. pectiniger. Since gill tissue did not yield enough nuclei for flow cytometry, we instead homogenized thoracic appendages in $500 \mu 1$ icecold LB01 detergent buffer and added rainbow trout blood cells as an internal standard. The homogenized tissue was filtered through a $30 \mu$ m nylon filter. We then added $12 \mu$ propidium iodide with $2 \mu \mathrm{R}$ Rase, and stained for one hour in the dark. All samples were run on an FC500 flow cytometer (Beckman-Coulter) using a 488nm blue laser, providing output as singleparameter histograms showing relative fluorescence between the standard nuclei and the shrimp nuclei. We found that both methods gave qualitatively similar estimates of genome size (10.88 versus $11.45 \mathrm{pg}$ for $S$. brooksi and 12.79 versus $14.72 \mathrm{pg}$ in $S$. pectiniger using FIAD and flow cytometry, respectively). The slight differences among the two methods could be due to differences in tissue nucleus compaction levels or differences in stain uptake by the nuclei, but are most likely due to differences in the tissues used for the two methods. We note the FIAD measurements from Synalpheus gill tissue and hemolymph gave tissue-specific differences of similar magnitude (Table S1).

\section{Chromosome preparation}

Ratios of 0.5 to $1.5: 10$ stock colchicine solution $(0.1 \% \mathrm{w} / \mathrm{v})$ were added to seawater containing a single live shrimp for 3-8 hrs. The best preparations resulted from 1.5:10 stock dilution with the shrimp in solution for $8 \mathrm{hrs}$, though exposure to colchicine for this long may result in chromosome condensation (Bogart, pers. comm.). Shrimp were then placed in deionized water for 30-60 min to allow the cells to swell. We then fixed the specimens in Carnoy's (3:1 ethanol:acetic acid) and held at $4^{\circ} \mathrm{C}$ in the refrigerator. Embryos and hepatopancreas were dissected out of the shrimp and placed in separate $1.5 \mathrm{ml}$ tubes in $100 \mu 170 \%$ (v/v) acetic acid to soften the tissue. The tissue was homogenized with a plastic pestle. The cell suspension was sucked into a glass pipette and dropped onto a glass microscope slide on a hot plate $\left(60^{\circ} \mathrm{C}\right)$ from a height of $\sim 30 \mathrm{~cm}$. The excess fluid was sucked back into the pipette and the process was repeated until several rings of cells were made on each slide. The slides were then immersed in 95\% EtOH and ignited by a Bunsen burner to fix the chromosomes to the slide. Each slide was stained in 5\% modified Giemsa solution (Sigma-Aldrich product GS500) for $20 \mathrm{~min}$. The slides were then rinsed in deionized water and allowed to air dry overnight. Images of chromosome 
spreads were taken at 100x magnification using a Leica DM LS compound microscope with mounted Optronics DEI-750 CE CCD camera and Bioquant Life Science software. Chromosome number was determined by counting distinct chromosomes on each slide, and chromosome size was measured using the Area function in the Bioquant software. Since our estimates of chromosome number were only approximate, we did not calculate estimates of variation. Additionally, we note that our success rate with these methods was quite low, likely because we found few ovigerous females whose embryos would provide a greater number of dividing cells than somatic tissue (Table S2).

\section{Statistical analyses}

We used a Wilcoxon signed-rank test to account for differences in variance and sample size to compare the mean IOD of male and female $S$. duffyi as a check for sex differences in genome size. The relationship between genome size and body size (measured as carapace length) was investigated using phylogenetic generalized least squares (PGLS) on log-transformed genome sizes and body sizes in the ape and nlme packages in R (Paradis et al. 2004, Pinheiro et al. 2013). The phylogenetic tree was taken from Hultgren and Duffy (2012). Blomberg's K (Blomberg et al. 2003) was calculated using the phytools package (Revell 2012) to determine the distribution of genome size in relation to the phylogenetic relatedness of the species. A value of $\mathrm{K}=1.0$ suggests the trait in question is evolving under Brownian motion, while lower values approaching zero indicate a departure from Brownian motion evolution. This function also provides a $\mathrm{p}$-value to determine if $\mathrm{K}$ is significantly different from a phylogeny with a randomized distribution. Because we only had estimates of chromosome size and number from four species, we used a General Linear Model (GLM) with the raw data to determine if chromosome number and size influenced genome size in these four species.

To determine if interspecific genome size variation among species was related to intraspecific geographic variation in genome size, or could be a result of differences in preservation time, we ran a GLM with site and year as fixed effects and the coefficient of variation in genome size as the dependent variable. If intraspecific variation in genome size was affected by geographic variation in genome size or variation in preservation time, we would expect a positive correlation between the coefficient of variation and these two variables. Additionally, for two species with the largest and most variable genomes ( $S$. duffyi and $S$. idios), 
we tested whether geographic variation in genome size was related to genetic divergence in the COI gene using intraspecific pairwise comparisons. In this case, we would expect a positive relationship between genome size and genetic divergence as well as a positive correlation between genetic divergence and geographic distance. For each of these species, we first ran a GLM with site as a fixed effect. Then, we separately regressed percent difference in genome size (|individual 1 - individual 2|* average (individual 1, individual 2)) by percent genetic divergence (Kimura 2-parameter distance converted to percent divergence). For $S$. duffyi, which resides in eusocial colonies (Anker and Tóth 2008), we examined divergence in genome size within a colony by collecting genome size data on 2-4 individuals per colony (often including the reproductive female queen) and calculating percent divergence amongst colony members $\left((\text { maximum genome size- minimum genome size })^{*}(\text { mean genome size })^{-1}\right)$.

\section{Results}

Interspecific diversity in genome size

Across the 39 species of Synalpheus, mean \pm SD genome sizes ranged from $4.83 \pm 0.69 \mathrm{pg}$ in $S$. thele to $20.74 \pm 2.28 \mathrm{pg}$ in $S$. duffyi, showing roughly 4-fold variation (Figure 1, Table S3). Phylogenetic signal of genome size was calculated as $\mathrm{K}=0.34$, indicating (1) a departure from a Brownian motion model of trait evolution and (2) that genome size similarity between relatives was less than expected, as in the case where $K \geq 1.0$. The phylogenetic signal was also not significantly different than expected from a randomized distribution $(\mathrm{P}=0.17)$. We observed no relationship between genome size and body size (carapace length) (phylogenetic generalized least squares [PGLS] using the Ornstein-Uhlenbeck model on log-transformed data: $F_{1,32}=$ $0.00051, \mathrm{P}=0.98$; Figure S1).

\section{Intraspecific patterns in genome size}

Several Synalpheus species exhibited high (i.e. $>10 \%$ ) intraspecific variation in genome size (Table S3). The coefficient of variation (CV) in genome size was not related to differences in the number of sites $\left(\chi_{1,35}=0.24, \mathrm{P}=0.62\right)$ or years sampled $\left(\chi_{1,35}=0.11, \mathrm{P}=0.74\right)$ for each species.

After an initial screen showed that the most intraspecific variation in genome size occurred in $S$. duffyi and $S$. idios - the two species with the largest genomes - we examined these species further by increasing our sampling within and among sites. We sampled $S$. duffyi in 
Florida, Jamaica, and Cuba and S. idios from Barbados, Belize, Florida, and Curaçao. Although there was on average $2.7 \%$ divergence in COI among $S$. duffyi populations, there was little population-specific difference in genome size $\left(\mathrm{F}_{3,41}=2.17, \mathrm{P}=0.11\right.$, Fig. 2$)$, and genome size variation was not correlated with COI divergence $(\mathrm{t}=-0.17, \mathrm{df}=64, \mathrm{P}=0.43)$. By contrast, while $S$. idios showed significant differences in genome size among populations $\left(\mathrm{F}_{3,18}=27.29, \mathrm{P}\right.$ $<0.0006)$, genome size variation was uncorrelated with COI divergence $(\mathrm{t}=0.45, \mathrm{df}=53, \mathrm{P}=$ 0.33). Specifically, despite 0\% COI divergence between Curaçao and Barbados, the Curaçao population had genome sizes that were on average 17.8\% larger than those in Barbados (Tukey HSD: $\mathrm{P}=0.0001$; Figure 2). Moreover, populations in Florida and Belize had on average 4.31\% COI divergence from Curaçao, and 27.1\% smaller genomes (Tukey HSD: $\mathrm{P}=0.001$ and $\mathrm{P}<$ 0.0001, respectively; Figure 2).

In addition to the observed among-population intraspecific variation in two species of Synalpheus, we also examined intra-colony variation in $S$. duffyi, which was sampled extensively from Jamaica and Florida. S. duffyi lives in large eusocial colonies, with one breeding female and associated colony members inhabiting a single sponge (Anker and Tóth 2008). S. duffyi from different sponges (i.e., colonies) from one site in Jamaica showed up to 35\% variation in genome size (range $=17.38$ to $24.66 \mathrm{pg}$ ). This variation did not appear to be related to differences in host sponges; although $S$. duffyi occurred in two different sponge species in Jamaica, there were no consistent differences in mean genome size between hosts $\left(\mathrm{F}_{1,5}=0.36, \mathrm{P}=0.57\right)$. To our surprise, we also observed high variation in genome size among $S$. duffyi individuals sampled from the same sponge; because in all cases these individuals were found with only one breeding female, we assumed that these individuals were from the same colony. In one $S$. duffyi colony from Jamaica (sponge 74), genome size varied 29\% among individuals ( $\mathrm{CV}=0.14$, range $=$ 18.14 to $23.86 \mathrm{pg}$ ); in three independent $S$. duffyi colonies from Florida (sponges 28, 49, 84), genome size varied from $25-30 \%$ within an individual colony $(\mathrm{CV}=0.13-0.15$, range $=16.65$ to $23.19 \mathrm{pg}$ ). We were unable to sample enough individuals to test the generality of this pattern in Cuban populations of $S$. duffyi.

To determine if these unexpected intra-colony differences in genome size could be related to sex, we measured the integrated optical densities (IODs) of gill nuclei from histologically sexed individuals that were previously embedded in paraffin. IOD was used as a proxy for genome size as this measure correlates strongly with DNA content across a wide range 
of genome sizes (Hardie et al. 2002). Since $S$. duffyi are likely sequential hermaphrodites and can only be sexed through histological analysis (Chak et al. 2015), our sampling was limited and we could not measure absolute genome size of these specimens because they were fixed in paraffin. Nonetheless, we observed no difference between the mean IODs of 4 male and 18 female shrimp $(\mathrm{W}=42, \mathrm{P}=0.65 ; 16291$ versus 15068 mean IOD for male and female, respectively).

\section{Chromosome number and size}

To determine if the large genome sizes in Synalpheus shrimps could be due to whole or partial genome duplication, we examined chromosome number and size in four species. Despite substantial differences in genome size, S. pectiniger $(\mathrm{GS}=12.79 \mathrm{pg})$ and S. ruetzleri $(\mathrm{GS}=6.57$ pg) had diploid chromosome counts of approximately $2 \mathrm{n}=80$ chromosomes. Similarly, $S$. brooksi $(\mathrm{GS}=10.88 \mathrm{pg})$ and $S$. williamsi $(\mathrm{GS}=6.44 \mathrm{pg})$ differed greatly in genome size, but had chromosome counts of approximately $2 \mathrm{n}=100$ (Figure 3). Genome size in these four Synalpheus species was positively related to chromosome size $\left(\mathrm{F}_{1,3}=4.88, \mathrm{P}=0.048\right)$, but not chromosome number $\left(\mathrm{F}_{1,3}=0.14, \mathrm{P}=0.11\right.$; Figure $\left.\mathrm{S} 2\right)$.

\section{Discussion}

Synalpheus shrimps exhibited high inter- and intra-specific variability in genome size. Among the 39 species in the gambarelloides group analyzed here, we observed a 4-fold variation in genome size across species. Despite strong variation in both body size and genome size in Synalpheus, we found no relationship between these two variables, suggesting that selection for differences in body size occurred independently of changes in genome size. Because there was also little phylogenetic signal in this diversity, genome size appears to be less conserved than expected among related species. This indicates a departure from a Brownian motion model of genome size evolution (Blomberg et al. 2003), and suggests that genome size varies continuously in some parts of the phylogeny, but shows discrete jumps in other parts. Across major eukaryotic clades, genome size has been suggested to evolve under a Brownian model of evolution, but this varies by taxon (Oliver et al. 2007).

We revealed evidence of high intraspecific variation in the two species with the largest genomes, $S$. duffyi and S. idios. Much of the variation within S. idios was due to geographic variation in genome size among populations from Florida, Belize, Barbados, and Curaçao. 
Geographic variation in genome size, however, could not be explained by genetic divergence among populations. Specifically, individuals from Curaçao had a consistently larger genome sizes than those from other populations, despite $0 \%$ COI divergence between Curaçao and Barbados populations. Conversely, while $S$. duffyi exhibits high COI divergence among populations (populations from Cuba were average 2.7\% divergent from populations in Florida and Jamaica), this genetic variation was not correlated with variation in genome size (Figure 2). This divergence in COI is consistent with divergence previously detected by Hultgren et al. (2014) who observed 1.2\% mean intraspecific divergence in COI within Synalpheus and 8.1\% divergence between sister species. Thus, the intraspecific variation in genome size observed in these two species of Synalpheus shrimps is not related to genetic population differentiation. This may imply that genome size has changed rapidly in the different populations.

We also observed variation in genome size among colonies of $S$. duffyi at a single site in Jamaica (up to $35 \%$ variation in genome size within a single colony), and within multiple individual colonies in Florida and Jamaica (up to 30\%). Although it is possible that this genome size variation is due to experimental error, it appears to be 'orthodox' sensu Greilhuber (2005), as there was no relationship between the time preserved in ethanol and genome size, the lighting was standardized for all slides to account for background darkness, and differences in nucleus size were not due to compaction level. Thus, the most likely explanation for these differences is the differential proliferation (and/or deletion) of transposable elements among populations. This hypothesis has previously been suggested as the mechanism of genome size variation in various plant species (e.g. Rayburn and Auger 1990, Bennetzen et al. 2005) but has not been studied in depth within animals or crustaceans specifically. Transposable elements have been characterized from different crustacean lineages (e.g. Casse et al. 2006, Vergilino et al. 2013), though their direct contributions to differences in genome size have not yet been quantified.

Previous studies of microsatellite data from multiple species of Synalpheus were consistent with a signature of genome duplication (Rubenstein et al. 2008), but our limited analysis of four species with genome sizes of approximately $6 \mathrm{pg}$ and 10-12 pg revealed no evidence of polyploidy (i.e. there was no correlation between genome size and chromosome number). Because we observed that genome size was positively correlated with chromosome size (but not number), segmental duplications or paleopolyploidy (i.e. ancient polyploidy in the lineage of the shrimps that may be difficult to detect due to duplicate gene deletion over 
evolutionary time; Garsmeur et al. 2014) may explain the microsatellite data (Rubenstein et al. 2008) and the large genome sizes in many species of Synalpheus. However, we cannot completely rule out that species with larger genomes, including $S$. duffyi and S. idios, may be polyploid relative to species with smaller genomes. Unfortunately, even after repeated tries, we were unable to get useable samples from $S$. duffy and $S$. idios, the two species with the largest genomes. Nonetheless, since we found a correlation between genome size and chromosome size in four species of Synalpheus, gene duplications or repetitive DNA - especially transposable element - proliferation (Kidwell 2002) are most likely to be the primary determinant of differences in genome size among Synalpheus shrimps.

In summary, we not only found extensive interspecific variation in genome size within the Synalpheus genus, but also widespread intraspecific variation within the two species that had the largest genomes, as well as intra-colony variation in one of these species. The next step in studying genome size evolution in Synalpheus will be to examine the reasons why some species show intraspecific variation within and among populations and others do not. Finally, additional quantitative data on behavior and phylogenetic relationships for Synalpheus in the gambarelloides group (especially for newly described species) will enable future studies on the relationships among genome size and other life history parameters (e.g. social system and reproductive mode), with important implications for the study of genome size evolution and diversification in this group.

\section{Conflict of Interest}

The authors declare there are no conflicts of interest.

\section{Acknowledgements}

We are grateful for advice from Dr. Jim Bogart and Ivo Oliveira for suggestions on chromosome preparations. We acknowledge J. Emmett Duffy for coordinating the long-term Synalpheus study and obtaining samples. N.W.J and T.R.G were supported by a National Sciences and Engineering (NSERC) Canada Graduate Scholarship and Discovery Grant, respectively. K.H. was supported by a Natural Sciences Grant from the M.J. Murdock Foundation. S. T.C.C. was funded by the Smithsonian Tropical Research Institute Short-Term Fellowship Program. D.R.R was supported by the US National Science Foundation (IOS-1121435, IOS-1257530). 


\section{References}

Alvarez-Fuster, A., Juan, C., and Petitpierre, E. 1991. Genome size in Tribolium flour-beetles: inter- and intraspecific variation. Genet. Res. 58: 1-5.

Anker, A., and Tóth, E. 2008. A preliminary revision of the Synalpheus paraneptunus Coutière, 1909 species complex (Crustacea: Decapoda: Alpheidae). Zootaxa 1915: 1-28.

Bachmann, K., and Rheinsmith, E.L. 1973. Nuclear DNA amounts in Pacific Crustacea. Chromosoma 43: 225-236.

Bennetzen, J.L., Ma, J., and Devos, K.M. 2005. Mechanisms of recent genome size variation in flowering plants. Ann. Bot. London 95: 127-132.

Blomberg, S.P., Garland Jr., T., and Ives, A.R. 2003. Testing for phylogenetic signal in comparative data: behavioral traits are more labile. Evolution 57: 717-745.

Bonnivard, E., Catrice, O., Ravaux, J., Brown, S.C., and Higuet, D. 2009. Survey of genome size in 28 hydrothermal vent species covering 10 families. Genome 52: 524-536.

Casse, N., Bui, Q.T., Niolas, V., Renault, S., Bigot, Y., and Laulier, M. 2006. Species sympatry and horizontal transfers of Mariner transposons in marine crustacean genomes. Mol. Phylogenet. Evol. 40: 609-619.

Chak, S.T.C., Duffy, J.E., and Rubenstein, D.R. 2015. Reproductive skew drives patterns of sexual dimorphism in sponge-dwelling snapping shrimps. P. Roy. Soc. Lond. B Bio. 282: 20150342.

De Bodt, S., Maere, S., and Van de Peer, Y. 2005. Genome duplication and the origin of angiosperms. Trends Ecol. Evol. 20: 591-597.

Deiana, A.M., Cau, A., Coluccia, E., Cannas, R., Milia, A., Salvadori, S., and Libertini, A. 1999. Genome size and AT-DNA content in thirteen species of Decapoda. In Crustaceans and the Biodiversity Crisis. Edited by Schram, F.R. and von Vaupel Klein, J.C. Koninklijke Brill NV, Leiden, The Netherlands. Pp. 981-985. 
Duffy, J.E. 1993. Genetic population structure in two tropical sponge-dwelling shrimps that differ in dispersal potential. Mar. Biol. 116: 459-470.

Duffy, J.E. 1996. Resource-associated population subdivision in a symbiotic coral-reef shrimp. Evolution 50: 360-373.

Duffy, J.E., and Macdonald, K.S. 2010. Kin structure, ecology and the evolution of social organization in shrimp: a comparative analysis. P. Roy. Soc. Lond. B Bio. 277: 575-584.

Dufresne, F., and Hebert, P.D.N. 1998. Temperature-related differences in life-history characteristics between diploid and polyploid clones of the Daphnia pulex complex. Ecoscience 5: 433-437.

Ellis, L.L., Huang, W., Quinn, A.M., Ahuja, A., Alfrejd, B., Gomez, F.E., Hjelman, C.E., Moore, K.L., Mackay, T.F.C., Johnston, J.S., and Tarone, A.M. 2014. Intrapopulation genome size variation in D. melanogaster reflects life history variation and plasticity. PLoS Genet. 10: e1004522.

Felder, D.L., and Chaney, A.H. 1979. Decapod crustacean fauna of Seven and One-Half Fathom Reef, Texas: species composition, abundance and species diversity. Contrib. Mar. Sci. 22: 1-29.

Garsmeur, O., Schnable, J.C., Almeida, A., Jourda, C., D’Hont, A., and Freeling, M. 2014. Two evolutionarily distinct classes of paleopolyploidy. Molec. Biol. Evol. 31: 448-454.

Gregory, T.R. 2015. Animal Genome Size Database. http://www.genomesize.com.

Gregory, T.R., and Mable, B.K. 2005. Polyploidy in animals. In The Evolution of the Genome. Edited by Gregory, T.R. Elsevier, San Diego. pp. 427-517. 
Greilhuber, J. 1998. Intraspecific variation in genome size: a critical reassessment. Ann. Bot. London 82: 27-35.

Greilhuber, J. 2005. Intraspecific variation in genome size in angiosperms: identifying its existence. Ann. Bot. London 95: 91-98.

Hardie, D.C., Gregory, T.R., and Hebert, P.D.N. 2002. From pixels to picograms: a beginners' guide to genome quantification by Feulgen image analysis densitometry. J. Histochem. Cytochem. 50: 735-749.

Hultgren, K.M., and Duffy, J.E. 2010. Sponge host characteristics shape the community structure of their shrimp associates. Mar. Ecol.-Prog. Ser. 407: 1-12.

Hultgren, K.M., and Duffy, J.E. 2011. Multi-locus phylogeny of sponge-dwelling snapping shrimps (Caridea: Alpheidae: Synalpheus) supports morphology-based species concepts. J. Crust. Biol. 31: 356-364.

Hultgren, K.M., and Duffy, J.E. 2012. Phylogenetic community ecology and the role of social dominance in sponge-dwelling shrimp. Ecol. Lett. 15: 704-713.

Hultgren, K.M., Hurt, C., and Anker, A. 2014. Phylogenetic relationships within the snapping shrimp genus Synalpheus (Decapoda: Alpheidae). Mol. Phylogenet. Evol. 77: 116-125.

Jeffery, N.W., and Gregory, T.R. 2014. Genome size estimates for crustaceans using Feulgen image analysis densitometry of ethanol-preserved tissues. Cytometry Part A 85: 862-868.

Kidwell, M.G. 2002. Transposable elements and the evolution of genome size in eukaryotes. Genetica 115: 49-63. 
Morrison, C., Rios, R., and Duffy, J. 2004. Phylogenetic evidence for an ancient rapid radiation of Caribbean sponge-dwelling snapping shrimps (Synalpheus). Mol. Phylogenet. Evol. 30: 563581.

Neiman, M., Beaton, M.J., Hessen, D.O., Jeyasingh, P.D., and Weider, L.J. 2015.

Endopolyploidy as a potential driver of animal ecology and evolution. Biol. Rev. (Published Online).

Oliver, M.J., Petrov, D., Ackerly, D., Falkowski, P., and Scholfield, O.M. 2007. The mode and tempo of genome size evolution in eukaryotes. Genome Res. 17: 594-601.

Paradis, E., Claude, J., and Strimmer, K. 2004. APE: Analyses of Phylogenetics and Evolution in R language. Bioinformatics 20: 289-290.

Piegu, B., Guyot, R., Picault, N., Roulin, A., Saniyal, A., Kim, H., Collura, K., Brar, D.S., Jackson, S., Wing, R.A., and Panaud, O. 2006. Doubling genome size without polyploidization: Dynamics of retrotransposition-driven genomic expansions in Oryza australiensis, a wild relative of rice. Genome Res. 16: 1262-1269.

Pinheiro, J., Bates, D., DebRoy, S., and Sarkar, D. 2013. nlme: linear and nonlinear mixed effects models. R package version 3.1-103. R Foundation for Statistical Computing, Vienna.

Rayburn, A.L., and Auger, J.A. 1990. Genome size variation in Zea mays ssp. mays adapted to different altitudes. Theor. Appl. Genet. 79: 470-474.

Revell, L.J. 2012. phytools: an R package for phylogenetic comparative biology (and other things). Method. Ecol. Evol. 3: 217-223.

Rheinsmith, E.L., Hinegardner, R., and Bachmann, K. 1974. Nuclear DNA amounts in Crustacea. Comp. Biochem. Phys. 48B: 343-348. 
Rios, R., and Duffy, J.E. 2007. A review of the sponge-dwelling snapping shrimp from Carrie Bow Cay, Belize, with description of Zuzalpheus, new genus, and six new species (Crustacea: Decapoda: Alpheidae). Zootaxa 1602: 3-89.

Rubenstein, D.R., McCleery, B.V., and Duffy, J.E. 2008. Microsatellite development suggests evidence of polyploidy in the social sponge-dwelling snapping shrimp Zuzalpheus brooksi. Mol. Ecol. Res. 8: 890-894.

Soltis, D.E., Albert, V.A., Leebens-Mack, J., Bell, C.D., Paterson, A.H., Zheng, C., Sankoff, D., dePamphilis, C.W., Wall, P.K., and Soltis, P.S. 2009. Polyploidy and angiosperm diversification. Am. J. Bot. 96: 336-348.

Tamura, K., Stecher, G., Peterson, D., Filipski, A., and Kumar, S. 2013 .MEGA6: Molecular Evolutionary Genetics Analysis Version 6.0. Mol. Biol. Evol. 30: 2725-2729.

Vergilino, R., Elliott, T.A., Desjardins-Proulx, P., Crease, T.J., and Dufresne, F. 2013. Evolution of a transposon in Daphnia hybrid genomes. Mob. DNA 4: 7.

Wood, T.E., Takebayashi, N., Barker, M.S., Mayrose, I., Greenspoon, P.B., and Rieseberg, L.H. 2009. The frequency of polyploid speciation in vascular plants. P. Natl. Acad. Sci. USA 106: 13875-13879

Wyngaard, G.A., and Rasch, E.M. 2000. Patterns of genome size in the copepoda. Hydrobiologia 417: 43-56.

Wyngaard, G.A., Rasch, E.M., Manning, N.M., Gasser, K., and Domangue, R. 2005. The relationship between genome size, development rate, and body size in copepods. Hydrobiologia 532: 123-137.

Zhang, L., and King, C.E. 1993. Life history divergence of sympatric diploid and polyploid populations of brine shrimp Artemia parthenogenetica. Oecologia 93: 177-183. 
1 Figure 1. (A) Phylogeny based on Hultgren and Duffy (2012) for 35 species of Synalpheus and

2 their associated genome sizes. (B) Genome sizes for the same 35 species of Synalpheus arranged

3 in ascending order. The dashed line indicates the mean genome size for all species.

5 Figure 2. Molecular phylogenies of (A) Synalpheus duffyi from samples collected in Cuba,

6 Florida, and Jamaica, and (B) Synalpheus idios from samples collected in Barbados, Curaçao,

7 Belize and Florida. Trees are based on COI; taxonomy and Genbank information are given in

8 Table S4. There was 0\% COI divergence between Barbados and Curaçao populations of S. idios,

9 but between 1.09 and $4.31 \%$ divergence among all other populations in both species. (C)

10 Histograms of genome sizes for $S$. duffyi and $S$. idios from each sampling location, showing

11 specimens also sequenced for COI (black bars) and specimens without COI sequences (gray

12 bars). Both species show similar distributions of genome size variation (top panels). $S$. duffyi

13 shows little variation in genome size among populations despite population divergence in COI.

14 In contrast, $S$. idios shows variation in genome size between Barbados and Curaçao despite $0 \%$

15 COI divergence.

17 Figure 3. Feulgen stained nuclei showing intraspecific differences in nucleus size between two

18 specimens of Synalpheus duffyi from the same site in Jamaica (A and B), nuclei from S. herricki

19 (C), and from $S$. idios (D). Giemsa-stained chromosome preparations from S. brooksi (E), $S$.

20 pectiniger $(\mathrm{F})$, S. ruetzleri $(\mathrm{G})$, and $S$. williamsi $(\mathrm{H})$. The scale bar represents $20 \mu \mathrm{m}$ for all 21 panels. 

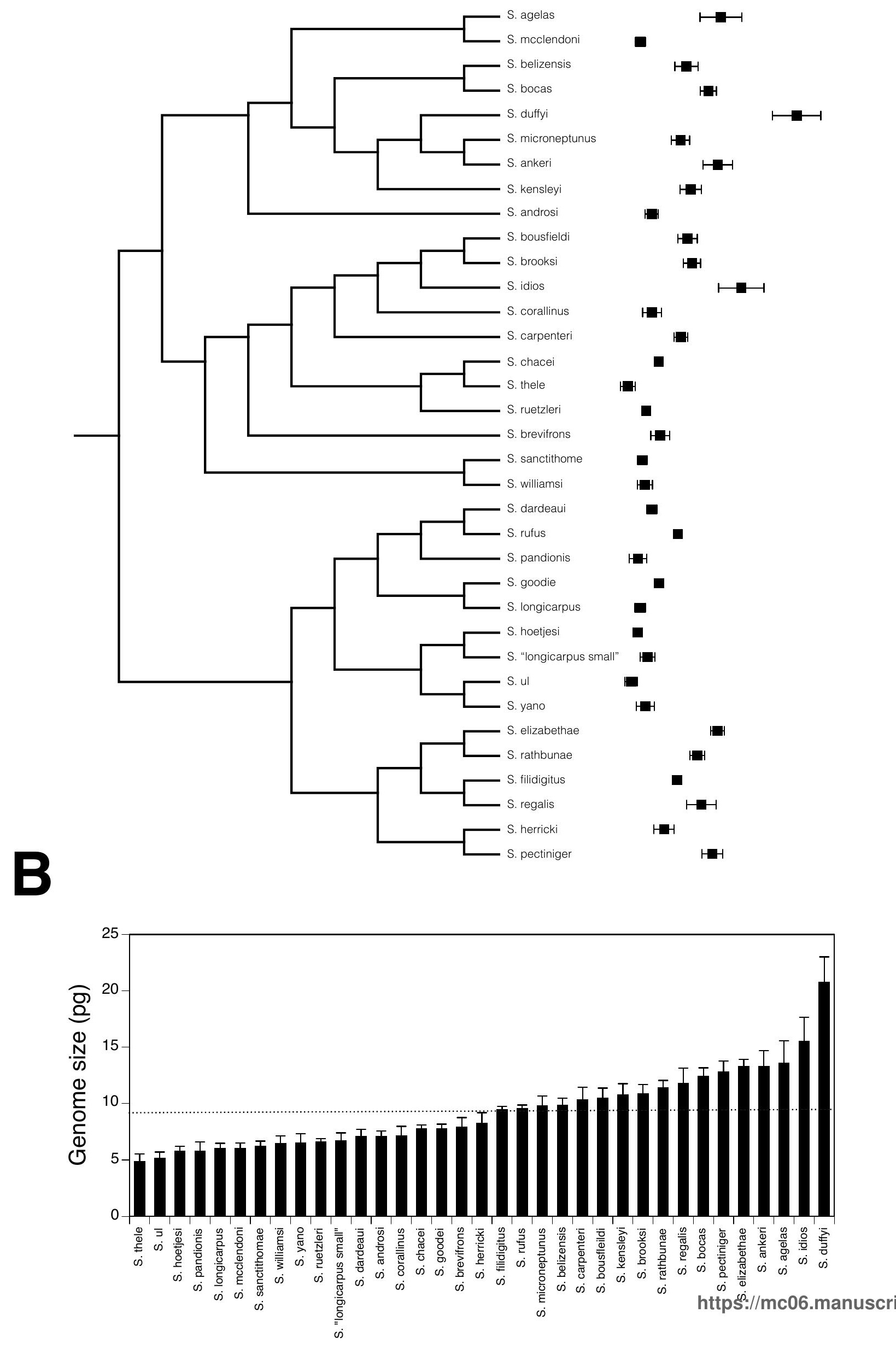


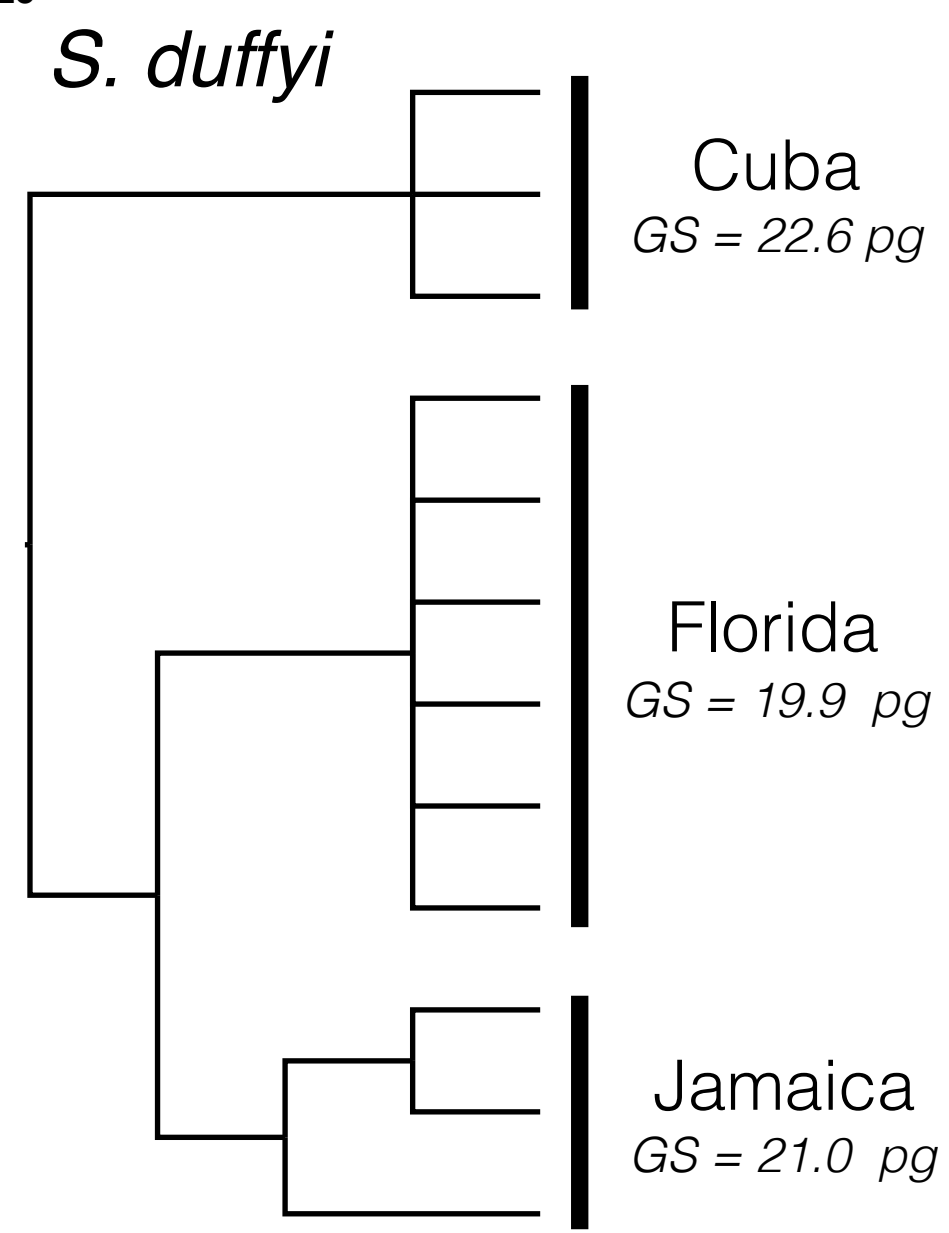

C
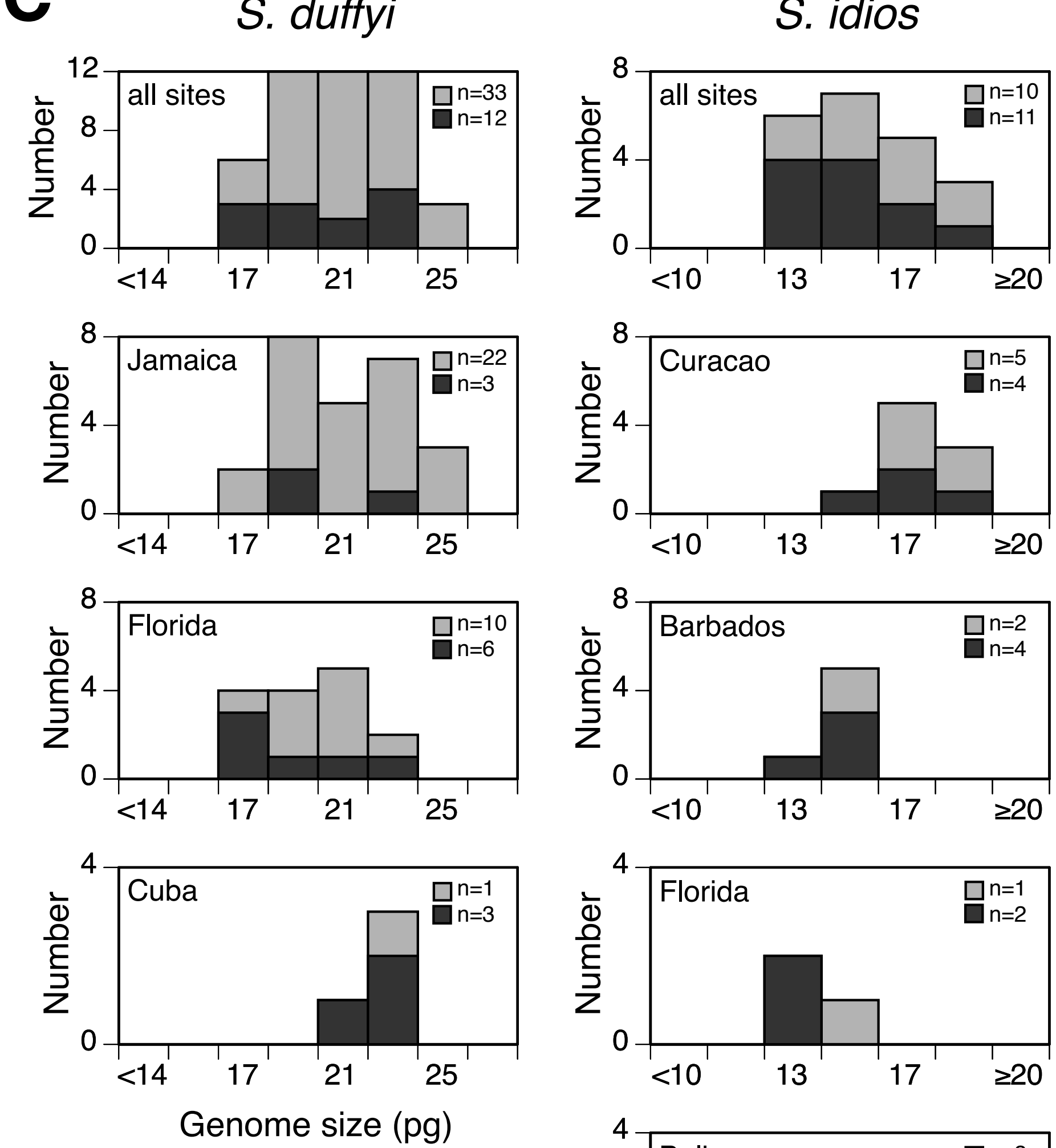

Curacao $G S=17.7 \mathrm{pg}$

S. idios

Barbados

$G S=14.8 \mathrm{pg}$

Genome size (pg)

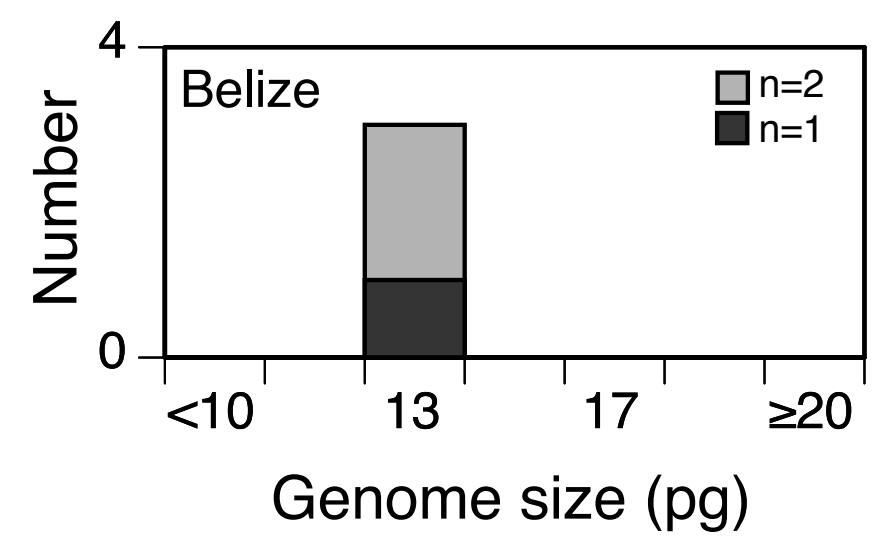



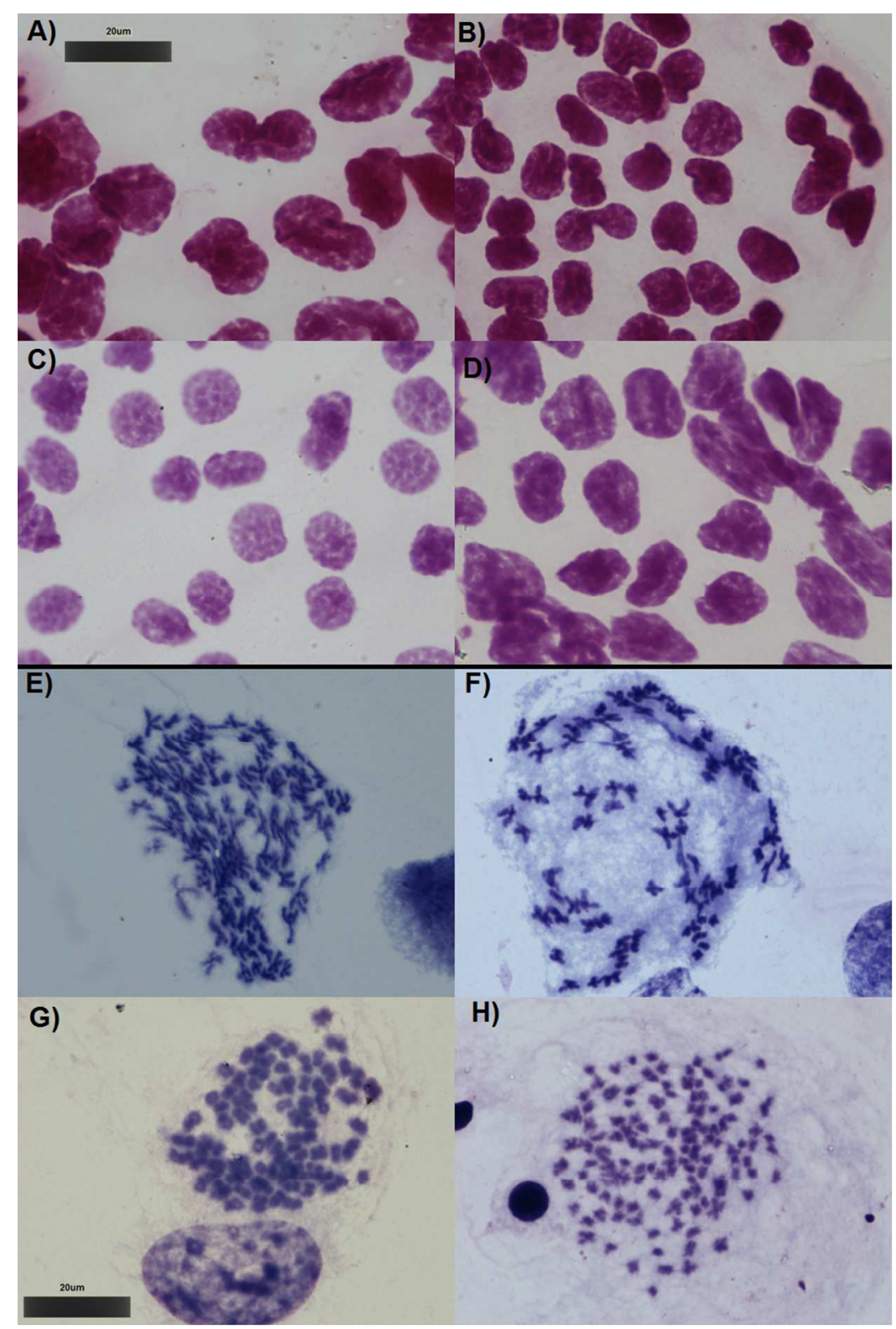

Figure 3. Feulgen stained nuclei showing intraspecific differences in nucleus size between two specimens of Synalpheus duffyi from the same site in Jamaica (A and B), nuclei from S. herricki (C), and from $S$. idios (D). Giemsa-stained chromosome preparations from S. brooksi (E), S. pectiniger (F), S. ruetzleri (G), and S. williamsi $(H)$. The scale bar represents $20 \mu \mathrm{m}$ for all panels 


\section{Supplementary Materials}

2 Table S1. Genome size estimates (in picograms) and sample sizes from gill tissue and

3 hemolymph for nine species of Synalpheus.

4

\begin{tabular}{lcccc}
\hline Species & \multicolumn{2}{c}{ Gill tissue } & & Hemolymph \\
\cline { 2 - 5 } & Mean \pm SD & n & Mean \pm SD & n \\
\hline S. agelas & $13.60 \pm 1.97$ & 7 & $19.30 \pm 0.76$ & 2 \\
S. belizensis & $10.35 \pm 1.09$ & 18 & 15.99 & 1 \\
S. brooksi & $10.88 \pm 0.80$ & 12 & 14.94 & 1 \\
S. carpenteri & $9.84 \pm 0.65$ & 10 & $12.15 \pm 0.67$ & 3 \\
S. dardeaui & $7.09 \pm 0.47$ & 9 & 7.99 & 1 \\
S. duffyi & $20.74 \pm 2.28$ & 45 & $27.90 \pm 1.68$ & 3 \\
S. mcclendoni & $6.01 \pm 0.49$ & 11 & $7.19 \pm 1.42$ & 3 \\
S. sanctithomae & $6.20 \pm 0.47$ & 9 & $7.81 \pm 0.54$ & 3 \\
S. yano & $6.49 \pm 0.85$ & 10 & $7.16 \pm 0.47$ & 3 \\
\hline
\end{tabular}


7 Table S2. Numbers of chromosome sample preparations and the number of successful 8 preparations for six species of Synalpheus.

9

\begin{tabular}{lcc}
\hline Species & Number sample preps & Number successful preps \\
\hline S. brooksi & 82 & 2 \\
S. ruetzleri & 55 & 2 \\
S. pectiniger & 54 & 2 \\
S. williamsi & 94 & 4 \\
S. idios & 40 & 0 \\
S. duffyi & 40 & 0 \\
\hline
\end{tabular}

10 
11 Table S3. Mean \pm SD genome size estimates reported in picograms (pg) for 39 Synalpheus

12 species, including coefficients of variation (CV), number of specimens analyzed (n), locality, and

13 years collected. Localities: Bah $=$ Bahamas, Bar $=$ Barbados, Bel = Belize, Cur $=$ Curaçao, Cub $=$

14 Cuba, Flo = Florida, Jam = Jamaica, Pan $=$ Panama.

15

\begin{tabular}{|c|c|c|c|c|c|}
\hline \multirow[t]{2}{*}{ Species } & \multicolumn{3}{|c|}{ Genome Size (pg) } & \multirow[t]{2}{*}{ Locality } & \multirow[t]{2}{*}{ Years Collected } \\
\hline & Mean \pm SD & CV & $\mathbf{n}$ & & \\
\hline S. ankeri & $13.30 \pm 1.39$ & 0.10 & 5 & Bel, Pan & $2001,2003-2005,2007$ \\
\hline S. agelas & $13.60 \pm 1.97$ & 0.14 & 7 & Bar, Cur, Jam & 2008,2012 \\
\hline S. androsi & $7.09 \pm 0.62$ & 0.09 & 9 & Bah, Bar, Bel, Jam & $2001,2004,2008,2012$ \\
\hline S. belizensis & $10.35 \pm 1.09$ & 0.11 & 18 & Bar, Bel, Cur, Jam & 1998, 1999, 2008 \\
\hline S. bocas & $12.42 \pm 0.76$ & 0.06 & 8 & Jam, Pan & $2008,2012,2013$ \\
\hline S. bousfieldi & $10.46 \pm 0.92$ & 0.09 & 9 & Bar, Bel, Cur & 2008,2012 \\
\hline S. brevifrons & $7.88 \pm 0.88$ & 0.11 & 8 & Bel, Cub, Jam & $2008,2009,2011$ \\
\hline S. brooksi & $10.88 \pm 0.80$ & 0.07 & 12 & Bel, Flo, Pan & $2005,2008,2009,2013$ \\
\hline S. carpenteri & $9.84 \pm 0.65$ & 0.07 & 10 & Bel, Cur, Jam, Pan & $2008,2009,2012$ \\
\hline S. cayoneptunus* & $13.15 \pm 1.02$ & 0.08 & 10 & Flo & 2013 \\
\hline S. chacei & $7.74 \pm 0.36$ & 0.05 & 9 & Bel, Pan & 2009 \\
\hline S. corallinus & $7.11 \pm 0.88$ & 0.12 & 4 & Jam & 2012 \\
\hline S. dardeaui & $7.09 \pm 0.47$ & 0.07 & 9 & Bel, Pan & 2009 \\
\hline S. dominicensis* & $5.79 \pm 0.28$ & 0.05 & 7 & Bar, Cub & 2008, 2011 \\
\hline S. duffyi & $20.74 \pm 2.28$ & 0.11 & 45 & Flo, Jam, Cub & $2008,2012,2013$ \\
\hline S. elizabethae & $13.28 \pm 0.63$ & 0.05 & 7 & Jam, Pan & 2008, 2009 \\
\hline S. filidigitus & $9.47 \pm 0.27$ & 0.03 & 4 & Bel & 2009 \\
\hline S. goodei & $7.78 \pm 0.39$ & 0.05 & 12 & Bel, Jam, Pan & 2009, 2012 \\
\hline S. herricki & $8.25 \pm 0.95$ & 0.12 & 16 & Bar, Bel, Cur, Flo & $2005,2008,2013$ \\
\hline S. "near herricki"* & $10.22 \pm 1.12$ & 0.11 & 4 & Jam, Pan & 2008, 2012 \\
\hline S. hoetjesi & $5.77 \pm 0.43$ & 0.08 & 10 & Bar, Cur & 2008 \\
\hline S. idios & $15.52 \pm 2.14$ & 0.14 & 22 & Bar, Bel, Flo, Cur & $2008,2009,2013$ \\
\hline S. kuadramanus* & 7.74 & & 1 & Jam & 2012 \\
\hline S. kensleyi & $10.76 \pm 1.01$ & 0.09 & 9 & Bel, Flo, Pan & $2002,2004,2007,2013$ \\
\hline S. longicarpus & $5.99 \pm 0.49$ & 0.08 & 3 & Flo & 2005 \\
\hline S. "longicarpus small" & $6.69 \pm 0.71$ & 0.11 & 10 & Bel, Pan & 2009 \\
\hline S. mcclendoni & $6.01 \pm 0.49$ & 0.08 & 11 & Bar, Cur, Jam & 2008,2012 \\
\hline S. microneptunus & $9.80 \pm 0.86$ & 0.09 & 8 & Bar & 2008 \\
\hline S. pandionis & $5.78 \pm 0.82$ & 0.14 & 12 & Bar, Bel, Jam & $2001,2003,2005,2008$ \\
\hline S. pectiniger & $12.79 \pm 0.98$ & 0.08 & 8 & Bah, Flo & 2001,2005 \\
\hline S. rathbunae & $11.38 \pm 0.68$ & 0.06 & 6 & Pan & 2008, 2009 \\
\hline S. regalis & $11.76 \pm 1.39$ & 0.12 & 10 & Bel, Jam & $2008,2009,2012$ \\
\hline S. ruetzleri & $6.57 \pm 0.32$ & 0.05 & 9 & Bel, Pan & 2008,2012 \\
\hline S. rufus & $9.54 \pm 0.34$ & 0.04 & 7 & Jam & 2008 \\
\hline S. sanctithomae & $6.20 \pm 0.47$ & 0.08 & 9 & Bar, Cur, Jam & 2008,2012 \\
\hline S. thele & $4.83 \pm 0.69$ & 0.14 & 11 & Bar, Jam & 2008 \\
\hline S. ul & $5.14 \pm 0.57$ & 0.11 & 12 & Bar, Bel, Cur, Jam, Pan & 2008,2009 \\
\hline S. williamsi & $6.44 \pm 0.71$ & 0.11 & 14 & Bar, Bel, Cur & 2008,2009 \\
\hline S. yano & $6.49 \pm 0.85$ & 0.13 & 10 & Bel, Pan & 2009 \\
\hline
\end{tabular}

16 * species not included in comparative analyses because they were not part of the Hultgren and Duffy (2012) phylogeny. 
17 Table S4. Taxonomic and collection information for S. duffyi and S. idios specimens used in 18 Fig. 2a-b (specimens are listed in the exact order that they are presented). Temp. \# refers to the 19 unique DNA template identifier, and VIMS collection \# refers to the Virginia Institute of Marine 20 Science specimen field code.

\begin{tabular}{ccccc}
\hline $\begin{array}{c}\text { Synalpheus } \\
\text { species }\end{array}$ & Temp.\# & Country & Collection \# & Genbank \# \\
\hline duffyi & 26 & Jamaica & VIMS 08JAM7401-2 & KJ595078 \\
idios & 156 & Curaçao & VIMS 08CU903 & KJ595104 \\
idios & 233 & Barbados & VIMS 08BR103 & KJ595105 \\
duffyi & 356 & Jamaica & VIMS 08JAM1203 & KJ595077 \\
duffyi & 849 & Jamaica & VIMS 12JAM12307 & KM204155 \\
duffyi & 883 & USA:Florida & VIMS 13FK02-1 & KM204161 \\
duffyi & 884 & USA:Florida & VIMS 13FK02-2 & KM204162 \\
duffyi & 915 & USA:Florida & VIMS 13FK8901 & KM204170 \\
duffyi & 916 & USA:Florida & VIMS 13FK8402 & KM204171 \\
duffyi & 919 & Cuba & VIMS 11CA2101 & KU682649 \\
duffyi & 932 & Cuba & VIMS 11CA102-1 & KM204173 \\
idios & 948 & Barbados & VIMS 08BR102-1 & KU682650 \\
idios & 949 & Barbados & VIMS 08BR6601 & KU682651 \\
idios & 951 & Curaçao & VIMS 08CU906 & KU682652 \\
idios & 952 & Curaçao & VIMS 08CU913 & KU682653 \\
idios & 953 & Curaçao & VIMS 08CU914 & KU682654 \\
idios & 971 & Barbados & VIMS 08BR6604-1 & KU682655 \\
duffyi & 973 & Cuba & VIMS 11CA1802-2 & KP265856 \\
duffyi & 975 & USA:Florida & VIMS 13FK4903 & KP265858 \\
duffyi & 976 & USA:Florida & VIMS 13FK8301-1 & KP265859 \\
idios & 1121 & Belize & VIMS 09CBC8806-3 & KU682656 \\
idios & 1123 & USA:Florida & VIMS 13FK7410 & KU682657 \\
idios & 1124 & USA:Florida & VIMS 13FK6603 & KU682658 \\
\hline & & & &
\end{tabular}


23 Figure S1. Relationship between genome size and carapace length (i.e. body size) for 34 species 24 of Synalpheus (see Table S1 for list of species).

25

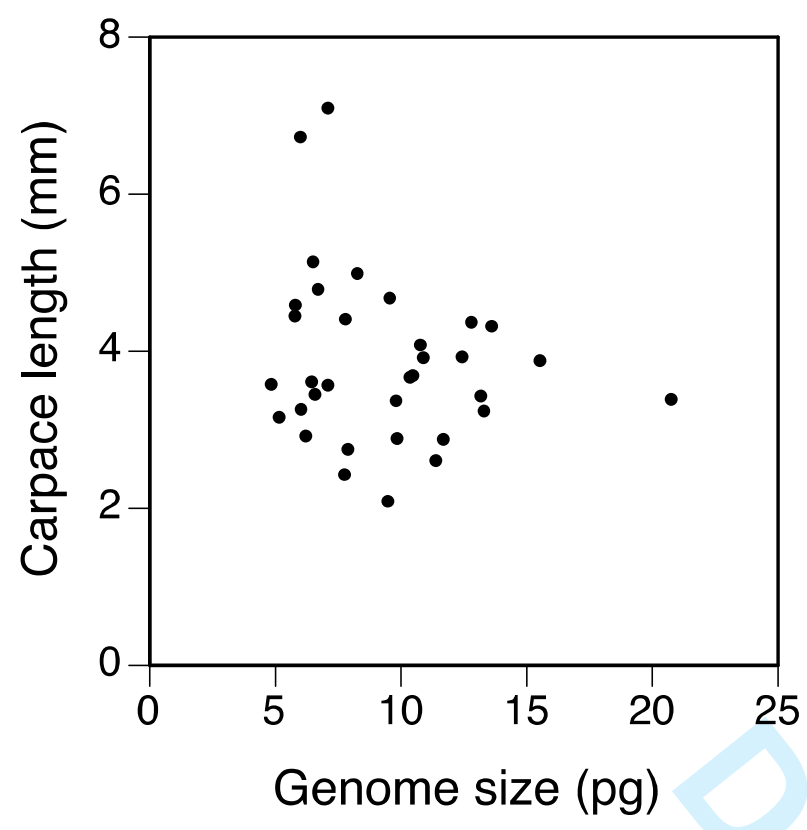


27 Figure S2. Relationship between mean \pm SE genome size and (A) mean chromosome number 28 and (B) mean \pm SE chromosome size (i.e. area) for four species of Synalpheus (see Table S2 for 29 list of species).

30

A

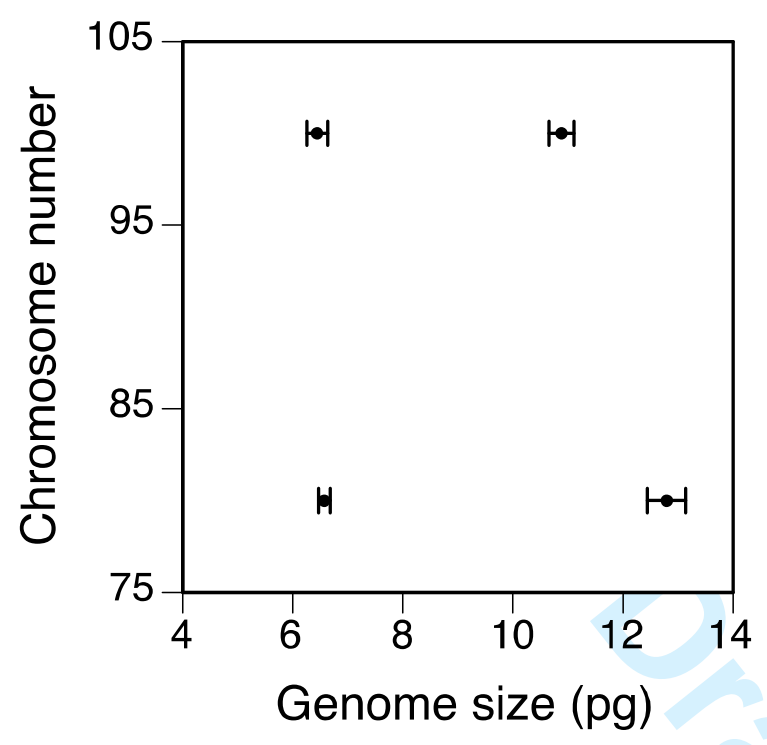

B

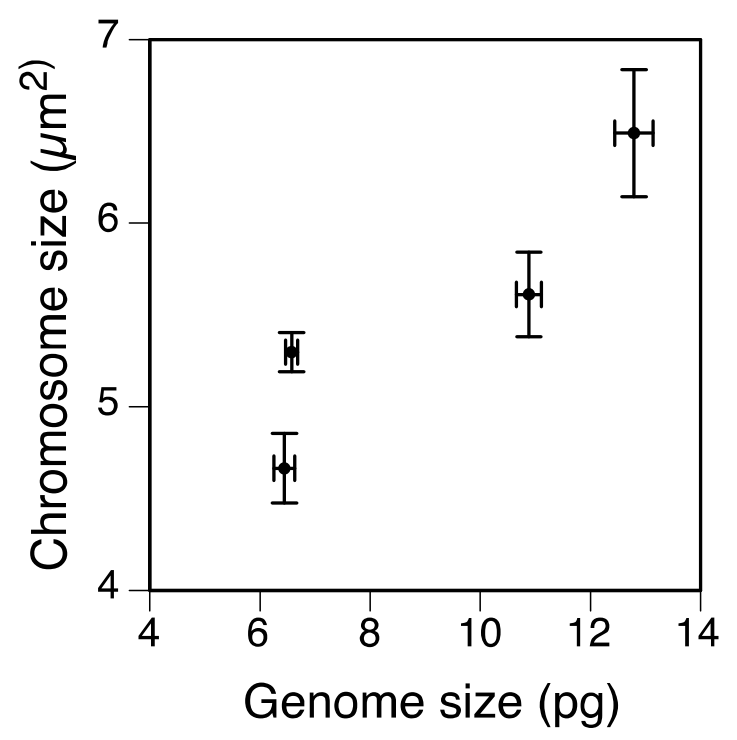

